\title{
Management of acute upper airway obstruction in an intensive care unit in a district general hospital
}

\author{
G H Lear, S A McKenzie, H Boralessa
}

Severe croup and epiglottitis are common causes of acute inflammatory upper airway obstruction that should be treated in intensive care units. These conditions are potentially life threatening and require immediate and skilled attention. Once the patient has been intubated, the principal aspects of management are efficient maintenance of the airway and good supportive care, and as long as mishaps are minimised, full recovery should result. ${ }^{1}$

There are not many paediatric intensive care units and those that there are, are often unable to accept transfers. The provision of paediatric beds in a district general hospital adult intensive care unit helps to overcome this difficulty, and has been advocated in a recent publication by the British Paediatric Association. ${ }^{2}$ If general intensive care units are to accept children routinely, however, it is important that the quality of care received is adequate, and does not fall far short of that offered in a specialist paediatric intensive care unit. The managment of acute upper airway obstruction is reasonably straightforward and should be confidently undertaken by any general intensive care unit that accepts children. Results from different units should be comparable, and could be used as a guide to the quality of care provided.

We present an account of our practice, and describe the results of a survey of five years' experience of the management of croup and epiglottitis in our general intensive care unit. We discuss the lessons learnt, and the implications for the organisation of facilities of children in general intensive care units.

\section{Oldchurch Hospital general intensive care unit}

This general intensive care unit serves one of the largest health districts in Britain, with a total population of 457000 of whom 83200 were under the age of 15 years in 1986. It has six beds, but only four are being used because of shortage of money. Although it is an adult unit, it admits more than 12 children a year. ${ }^{2}$ Two cubicles are available, and in 1986 one of these was designated for paediatric intensive care. Parents are encouraged to stay with their children, and accommodation is provided. The unit is under the direction of a full time consultant anaesthetist who liaises with the referring consultant paediatrician about the care of each child on the unit; she is responsible for all the main decisions. Two registrars in anaesthetics are resident round the clock. Some of the nursing staff are trained in intensive care, but not specifically trained in paediatrics, although inservice training has been made possible by rotating children's nurses through the unit.

\section{Clinical presentation}

For this discussion the definitions given below have been used. Epiglottitis presents as a respiratory illness with a short constitutional upset, the most striking feature of which is muffled stridor without cough. An oedematous, and usually extremely inflamed, epiglottis is seen at laryngoscopy. The aetiological agent is Haemophilus influenzae, which is usually cultured from the blood. Croup (laryngotracheobronchitis) may be of viral or bacterial origin. The common viral croup is usually caused by the parainfluenza virus, and presents as an upper respiratory tract infection that progresses to a barking cough and harsh stridor. Bacterial or pseudomembranous croup presents in the same way, ${ }^{3}$ but is often accompanied by constitutional upset and at intubation copious pus can be aspirated from the trachea, and pathogens such as Staphylococcus aureus and $H$ influenzae are grown.

Most children with severe stridor present directly to the accident and emergency department and are admitted straight to the general intensive care unit. Some are referred from neighbouring hospitals where intensive care facilities for children are not available (the longest journey being six miles), and some are initially admitted to the general paediatric ward and transferred to the general intensive care unit when they deteriorate.

\section{Management}

INITIAL ASSESSMENT

There is a well established protocol for admission. A child presenting to the accident and emergency department with severe stridor is seen by both the paediatric and anaesthetic registrars who perform a rapid clinical assessment, but without examining the throat. The child is then accompanied to the unit by a doctor equipped to resuscitate if necessary. The children's cubicle is prepared before arrival on the unit. This includes anaesthetic equipment, resuscitation trolley, a selection of laryngo- 
scopes, endotracheal tubes (cut to size), and accessories for difficult intubation. All equipment is checked daily.

Nowadays we do not take lateral neck radiographs or use mist inhalation or corticosteroids in the acute phase of the disease, as none of these has been proved to be of value. ${ }^{4}$ Nebulised adrenaline ( $1 \mathrm{ml}$ of $1 / 1000$ added to $5 \mathrm{ml}$ of normal saline) is occasionally used as an emergency measure while preparations are made to intubate.

\section{IMMEDIATE TREATMENT}

The decision about whether to laryngoscope the patient is made jointly by the senior members of the paediatric and anaesthetic teams. If required, laryngoscopy is done under general anaesthesia with halothane and oxygen. Swabs from the upper airway and tracheal aspirate are taken for culture, and the trachea is intubated orally to relieve the obstruction. A nasogastric tube is passed, and venous and arterial access obtained. If a diagnosis of epiglottitis is made, the first dose of chloramphenicol is given immediately. The patient is now stable, and a nasotracheal tube is passed; the diameter must permit a leak when an inspiratory pressure of 25 $\mathrm{cm} \mathrm{H}_{2} \mathrm{O}$ is applied. The nasotracheal tube is attached to a Tungstall connector, which is secured to the patient's face by two $1 \mathrm{~cm}$ zinc oxide tapes. The connector is also fixed by its wire attachment to the patient's forehead, protected with paediatric felt, and further secured by a head band of sticking plaster $5 \mathrm{~cm}$ wide.

Safe intubation requires the skill of an experienced anaesthetist, who in this unit is at least of registrar status. Under conditions such as these unsuccessful intubation has not been reported in several series. ${ }^{5-8}$ In common with other authors we have found the presence of an ear, nose, and throat surgeon unnecessary. ${ }^{79}$

Such a protocol should avoid the admission of a severely ill child to an inappropriate place (such as a busy paediatric ward) where severe deterioration and even death may occur. ${ }^{110}$ The only death from upper airway obstruction in this district during the five year study period occurred when a 23 month old boy with croup severe enough to cause cyanosis was admitted to an infectious diseases unit without paediatric supervision; he died six hours later.

\section{INDICATIONS FOR INTUBATION}

Laryngoscopy is undertaken in children with clinically severe upper airway obstruction. Useful indicators are the presence of exhaustion, increasing respiratory effort, and hypoxaemia not readily reversed by oxygen given by face mask or head box (assessed by colour, neurological state, and pulse oximetry). Small infants are intubated earlier, particularly those under 1 year of age, as are children with known upper respiratory tract disease such as subglottic stenosis, and those who had a prolonged period of neonatal ventilation. Laryngoscopy is deferred in children who do not have symptoms or signs suggestive of epiglottitis or bacterial croup, and who are only moderately stressed.

\section{SUBSEQUENT MANAGEMENT}

After intubation we establish the child on continuous positive airway pressure of $4-5 \mathrm{~cm} \mathrm{H}_{2} \mathrm{O}$ with inspiratory assist of $5-7 \mathrm{~cm} \mathrm{H}_{2} \mathrm{O}$ with a Servo 900C ventilator (Siemens-Elema). This reduces the work of breathing and minimises the effects of sedation. Sedation was initially by bolus doses of papaveretum and diazepam, with Althesin (alphaxalone/alphadolone-no longer available) for uncomfortable procedures. The intermittent sedation achieved, however, and the frequency of accidental extubation, led us to adopt continuous morphine infusion ( $0.01-0.02$ $\mathrm{mg} / \mathrm{kg} /$ hour) with additional boluses of chloral $(35 \mathrm{mg} / \mathrm{kg}$ ) if necessary every three to four hours through the nasogastric tube. Intravenous fluids are initially restricted to two thirds of maintenance requirements. Nasogastric feeds are usually introduced within 24 hours of intubation. Chloramphenicol ( $100 \mathrm{mg} / \mathrm{kg} /$ day $)$ is given for epiglottitis. For bacterial croup, flucloxacillin and ampicillin are given initially, with adjustment later according to bacterial sensitivities. Most children who are intubated for viral croup also receive a broad spectrum antibiotic (usually ampicillin) for prophylaxis. Subsequent management is carried out jointly by the paediatric and anaesthetic teams.

We give dexamethasone $(0 \cdot 1 \mathrm{mg} / \mathrm{kg} /$ dose every six hours) during the 24 hours before extubation to children who have either been intubated for prolonged periods or who have been reintubated several times to try and reduce subglottic oedema. Nebulised adrenaline is used if the child has severe stridor after extubation.

\section{Complications 1983-7}

We examined the medical and nursing records of all children who were admitted to the general intensive care unit during the years 1983-7 with a diagnosis of croup (viral or bacterial) or epiglottitis.

During the five year study period a total of 66 children with acute upper airway obstruction were admitted, of whom 36 were intubated (table 1). A further 68 children were intubated for other reasons. $H$ influenzae was grown from the blood in eight of the 12 cases of epiglottitis, and there were no instances of bacterial resistance to chloramphenicol. There were no definite cases of bacterial croup until 1987. The organisms involved were $\beta$ haemolytic streptococcus group A, $H$ influenzae, and in one case both $H$ influenzae and Streptococcus pneumoniae.

Table 1 Number of patients admitted to the intensive care unit with each disease by year of admission

\begin{tabular}{lcccc}
\hline Year & \multicolumn{2}{l}{ Viral croup } & Epiglotitis* & $\begin{array}{l}\text { Bacterial } \\
\text { croup }\end{array}$ \\
\cline { 2 - 5 } & $\begin{array}{l}\text { Total } \\
\text { No }\end{array}$ & No intubated & & \\
\hline 1983 & 8 & 4 & 1 & 0 \\
1984 & 11 & 4 & 6 & 0 \\
1985 & 10 & 1 & 3 & 0 \\
1986 & 9 & 6 & 1 & 0 \\
1987 & 13 & 6 & 1 & 3 \\
\hline Total & 51 & 21 & 12 & 3 \\
\hline *All children with & epiglottitis & and bacterial croup were
\end{tabular}
intubated. 
Table 2 Characteristics of patients and summary of management

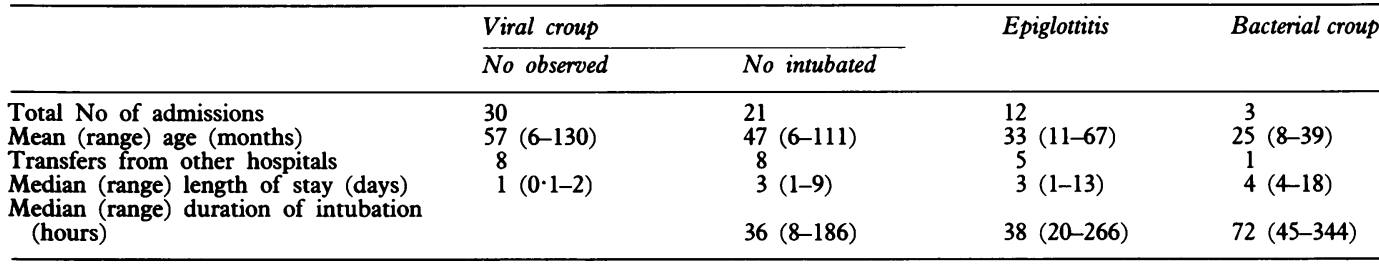

Table 3 Complications in intubated patients

\begin{tabular}{lcccc}
\hline & Viral croup & Epiglottitis & Bacterial croup & Total No \\
\hline Accidental extubation & 6 & 3 & 1 & 10 \\
Reintubation after failed elective extubation & 3 & 1 & 1 & 5 \\
Endotracheal tube block & 4 & 2 & 3 & 6 \\
Pulmonary shadowing & 6 & 3 & 1 & 12 \\
Urinary retention & 4 & 6 & 1 & 11 \\
Inappropriate secretion of antidiuretic hormone & 2 & 2 & 1 & 2 \\
Neurological abnormality at follow up & 0 & 2 & 1 & 7 \\
Others & 4 & 11 & 3 & 27 \\
\hline Total No of patients with complications & 13 & 1 & 0 & 9 \\
Total No of patients without complications & 8 & &
\end{tabular}

The age ranges and duration of intensive management are shown in table 2. Twenty two patients were transferred from other hospitals, six having been intubated before transfer.

Complications occurred in 27 of 36 intubated patients (table 3 ). They could be divided into two groups-those primarily associated with management, and those primarily associated with the disease itself. Some (such as retention of urine) clearly fell into the former category, whereas others (such as pulmonary shadowing on chest radiographs) were of less obvious cause. Table 3 shows the numbers of patients who experienced each complication, and it is evident that some had multiple problems. Of the 36 children intubated, 14 had one complication, eight had two, and six had three or more. Only nine patients had uncomplicated courses. Seventeen patients had complications associated with their endotracheal tubes. Other acute complications were pulmonary oedema $(n=2)$, one of which was associated with overt fluid overload, one apnoeic episode after the administration of papaveretum for sedation after intubation, one episode of bronchospasm probably as a result of aspiration, hypothermia after the initial intubation, and fluid overload leading to periorbital oedema. One child had a prolonged bradycardia after accidental extubation, and during a difficult reintubation went on to cardiac arrest from which he was successfully resuscitated. This child, who had bacterial croup, had a minor neurological deficit at follow up (mild weakness of one leg). The other neurological complication occurred in a child with $H$ influenzae septicaemia who also had a difficult clinical course with inappropriate secretion of antidiuretic hormone and convulsions; he now has overall development delay. His previous development, however, was said to have been slow, and it is difficult to assess the part played by the acute illness. There were no deaths during this period.
Should a general intensive care unit admit children?

The number of patients requiring respiratory support for acute inflammatory upper airway obstruction in our unit was larger than those in two recent series. ${ }^{9} 10$ This may reflect the size of the catchment area, as demographic data for comparison are given in only one of these reports. The intubation rate/100 000 child population (less than 15 years old) each year in our district was 8.7 , compared with 4.0 in Northampton. The intubation rates for epiglottitis were 2.9 and $2 \cdot 7$, respectively, and the difference may be the result of either a higher incidence of severe croup or of a lower threshold for intervention in our district. In 1987 we intubated 10 children for acute upper airway obstruction, and if this is typical of other districts the extra workload on a regional unit resulting from referral of these children would be considerable. The case for continuing to manage these problems in the district hospital is strong purely on numerical grounds.

Potential disadvantages of a general intensive care unit include the lack of trained paediatric nursing staff, the lack of specialist paediatric services, and the comparatively small number of children admitted.

Although only 36 children required intubation for upper airway obstruction during the five years of our survey, they remained intubated for a cumulative total of 93 days. Including other diagnoses, a total of 104 children required airway support during this period, which provided adequate experience for staff in the general intensive care unit to maintain their skills in caring for critically ill children.

Conversely, management in a local unit has some advantages over transfer to a paediatric intensive care unit. The journey itself may be dangerous in that the disturbance and anxiety caused to a child with one of these diseases may provoke acute obstruction, and even if intu- 
Table 4 Number of patients experiencing problems associated with endotracheal intubation in previous series and in the present series

\begin{tabular}{|c|c|c|c|c|c|}
\hline Series & $\begin{array}{l}\text { Place where treatment } \\
\text { carried out }\end{array}$ & $\begin{array}{l}\text { No of } \\
\text { intubated } \\
\text { patients }\end{array}$ & $\begin{array}{l}\text { Accidental } \\
\text { extubation }\end{array}$ & $\begin{array}{l}\text { Reintubation after } \\
\text { failed elective } \\
\text { extubation }\end{array}$ & $\begin{array}{l}\text { Blockage } \\
\text { of endotracheal } \\
\text { tube }\end{array}$ \\
\hline $\begin{array}{l}\text { Schuller and Birck }(1975)^{7} \\
\text { Breivik and Klaastad }\end{array}$ & Paediatric intensive care unit & 86 & 9 & 16 & Not recorded \\
\hline $\begin{array}{l}\text { Schloss et al }(1983)^{8} \\
\text { Welch and Price }(1983)^{9} \\
\text { Present series }(1988)\end{array}$ & $\begin{array}{l}\text { University hospital } \\
\text { Paediatric intensive care unit } \\
\text { General intensive care unit } \\
\text { General intensive care unit }\end{array}$ & $\begin{array}{r}18 \\
118 \\
52 \\
36\end{array}$ & $\begin{array}{r}4 \\
6 \\
18 \\
10\end{array}$ & $\begin{array}{l}1 \\
\text { Not recorded } \\
7 \\
5\end{array}$ & $\begin{array}{l}\text { Not recorded } \\
3 \\
4 \\
6\end{array}$ \\
\hline
\end{tabular}

bated before transfer there is always the danger of accidental extubation. A longer journey for the parents may make visiting or living in a regional centre inconvenient-and sometimes virtually impossible if they are reliant on public transport, especially in rural areas. Local management allows for continuity of follow up in the event of complications.

If a general intensive care unit is to accept children its staff must be prepared to audit their results and to modify their management as necessary. Survival in our series was $100 \%$, but the incidence of complications causes us concern.

\section{Lessons learnt}

MEDICAL

Several authors have described the complications of intensive management of upper airway obstruction in children, but most report only those associated with the respiratory system. Changes in chest radiographs are common and may be the result of the primary disease as well as of complications of management. The incidence in the present study compares well with those reported in several series. ${ }^{8} 11-13$

We have compared our incidence of problems associated with endotracheal intubation with those in previous studies in both paediatric intensive care units and a general intensive care unit (table 4). This type of complication may well be under-reported, as it was notable in reviewing case notes for this survey that problems associated with intubation were often not recorded in the medical notes, and the true incidence was only appreciated after careful study of the nursing records. We found that accidental extubation was associated with the level of sedation achieved, and have recently changed our policy from the use of intermittent boluses of sedative to continuous infusion of morphine; we anticipate that this will give better control. The achieving of adequate sedation, however, also leads to problems; urinary retention was common, and 10 children required catheterisation. Acute retention may cause restlessness, which predisposes to extubation, and an indwelling urinary catheter should be used when necessary. Some authors have reported that nasotracheal intubation without sedation is well tolerated, but it may then be necessary to restrain the child to avoid extubation. ${ }^{6} 1415$ The use of sedation thus represents a compromise. We feel that the disadvantages in terms of complications are outweighed by the advantages of reduced risk of extubation and of allowing the child to sleep through the whole unpleasant experience, but we also recognise that we must attempt to find a more effective balance to reduce the incidence of urinary retention.

Fluid management should be carefully considered. Judicious fluid restriction is advisable initially as five of our patients had hyponatraemia and high urinary osmolality, which are indicative of inappropriate secretion of antidiuretic hormone; in two others fluid overload was evident clinically, and in one patient it resulted in pulmonary oedema. This is a known complication of the relief of upper airway obstruction and should be anticipated. ${ }^{16}$

The long term complication rate was low, and again is comparable with previous studies. ${ }^{711}$ Most complications did not lead to serious problems, and the two patients with neurological effects had experienced stormy courses with cardiac arrest and repeated convulsions, respectively.

\section{IMPLICATIONS FOR STAFFING AND EDUCATION}

It is notable that only nine intubated patients did not have any complications at all, indicating that staff must be vigilant in detecting problems so that appropriate treatment can be started early to avoid deterioration. Planning is essential before embarking on the care of paediatric patients, and should include the establishment of a good working relationship between consultant paediatrician and anaesthetist, an understanding that junior staff are to be resident onand dedicated to-the general intensive care unit, and provision for cover for the absence of senior colleagues. Senior paediatricians and anaesthetists should visit the unit daily, to avoid errors in management such as unnecessary delay in elective extubation.

The continuing education of nursing and medical staff is a necessary aspect of intensive care in the district, and inservice training should be provided. Paediatric intensive care is stressful for junior staff, and consultant staff must be prepared to give adequate supervision and support; this may represent a problem where the sites are split.

As with any child in hospital, the critically ill child on the general intensive care unit must be cared for by staff who appreciate the needs of the child. Although specialist children's nurses are preferable, we have found that nursing staff need not be specifically trained in paediatrics to acquire the necessary skills, and that the atmosphere on the general intensive care unit is calming and pleasant for both child and parents. At least one parent is encouraged to be present at 
all times. The relief of anxiety is of particular importance in the management of airway obstruction.

\section{Conclusion}

Despite having encountered a number of problems we now feel confident in the management of upper airway obstruction in a district general hospital intensive care unit that caters for a mixed adult and child population, and which in 1987 admitted 53 children under the age of 15 years.

The requirement for paediatric intensive care exceeds the provision of facilities in specialist paediatric intensive care units, and the British Paediatric Association Working Party recommendations must therefore be implemented. ${ }^{2}$ We stress the importance of the phrase 'identified general intensive care units', which implies that paediatric intensive care should perhaps not be attempted in every general intensive care unit but limited to those with appropriate facilities and strong motivation of senior staff. We cannot agree with the implication in a recent editorial that the 'occasional' child could be looked after safely in district units. ${ }^{17}$ By concentrating efforts in designated general intensive care units, sufficient numbers of children should be managed to ensure that skills are maintained and that inservice training is available.

The incidence of complications associated with endotracheal intubation in the manage- ment of upper airway obstruction might be used as an 'indicator' in the audit of paediatric intensive care in a general intensive care unit provided that each incident is honestly documented.

1 Duncan PG. Management of upper airway disease in children. In: Gregory GA, ed. Respiratory failure in the child. New York: Churchill Livingstone, 1981:53-66.

2 Working party. Report on paediatric intensive care. London: British Paediatric Association, 1987.

3 Henry RL, Mellis CM, Benjamin B. Pseudomembranous croup. Arch Dis Child 1983;58:180-3.

4 Couriel JM. Management of croup. Arch Dis Child 1988;63: 1305-8.

5 Battaglia JD, Lockhart CH. Management of acute epiglottitis by nasotracheal intubation. Am $\mathcal{F}$ Dis Child 1975;129: 334-6.

6 Barker G. Current management of croup and epiglottitis. Pediatr Clin North Am 1979;26:565-79.

7 Schuller DE, Birck HG. The safety of intubation in croup and epiglottitis: an eight year follow-up. Laryngoscope 1975; 85:33-46.

8 Schloss MD, Gold JA, Rosales JK, et al. Acute epiglottitis: current management. Laryngoscope 1983;93:489-93.

9 Welch DB, Price DG. Acute epiglottitis and severe croup. Experien.

10 Evans NJ, Omenaka IL, Harper JR. Paediatric intensive care in district general hospital. Arch Dis Child 1988;63:31-4. 11 Breivik H, Klaastad O. Acute epiglottitis in children. $\mathrm{Br} \mathcal{F}$ Anaesth 1978;50:505-9.

12 Hodge KM, Ganzel TM. Diagnostic and therapeutic efficiency in croup and epiglottitis. Laryngoscope 1987;97: 621-5.

13 Davis HW, Gartner JC, Galvis AG, et al. Acute upper airway obstruction: croup and epiglottitis. Pediatr Clin North Am 1981;28:859-80.

14 Kilham H, Gillis J, Benjamin B. Severe upper airway obstruction. Pediatr Clin North Am 1987;34:1-14.

15 Butt W, Shann F, Walker C, et al. Acute epiglottitis: a different approach to management. Crit Care Med 1988;16: 43-7.

16 Travis KW, Todres I, Shannon DC. Pulmonary edema associated with croup and epiglottitis. Pediatrics 1977;59:

17 Editional. Paediatric intensive care units. Lancet 1987;ii:894. 